\title{
REPERTOIRE OF THE ACOUSTIC COMMUNICATION OF THE AZURE JAY CYANOCORAX CAERULEUS (VIEILLOT) (AVES, CORVIDAE)
}

\author{
Luiz dos Anjos 1 \\ Jacques M. E. Vielliard ${ }^{2}$
}

\begin{abstract}
The vocal repertoire of the Azure Jay Cyanocorax caeruleus (Vieillot, 1818) is approached from a quali-quantitative point of view. The qualitative analysis was carried out both in the field and in captivity: the quantitative analysis was made only in captivity. Social acoustic communication in the Azure Jay is achieved through the use of two types of call: basic and intermediate calls. Fourteen basic calls are identified and presented through sonograms: the sotto voce song (courtship call) is related only to courtship and the social call is interpreted as the song in the Azure Jay. The intermediate calls are recombinations of the basic calls uttered during an alteration in motivation level. Examples of them are presented through sonograms of vocalizations recorded during mobbing predators and intraspecific agonistic contexts. The social, social-alarm, contact, flight, proximity, threat and social identity calls were those most frequently uttered by daylight: the other calls represented around $15 \%$ of the total number of utterances. The hypothesis of the evolution in American Jays, which tends to simplification of vocal repertoire (HARDY, 1961; 1969), is analysed; C. caeruleus seems to have a small actively-used repertoire.
\end{abstract}

KEY WORDS. Aves, Corvidae, Cyanocorax caeruleus, repertoire, behavior

Among the species of New World Jays (family Corvidae), whose vocalizations are fairly well known (HARDY, 1984), several species exhibit a large repertoire.

The goal of this study is to analyse the vocal repertoire of the Azure Jay Cyanocorax caeruleus (Vieillot, 1818), a South American species, through a quali-quantitative approach in relation to general ethological contexts.

\section{METHODS}

Observations and recordings were carried out on the Santa Rita Farm in Palmeira county, $70 \mathrm{~km}$ west of Curitiba, in the Southern State of Paraná, Brazil, from July 1985 to June 1987 . Observations and recordings were also carried out using five captive individuals, including one juvenile. The development of this juvenile was studied in the laboratory from the age of 24 to 51 days.

1) Departamento de Biologia Animal e Vegetal, Universidade Estadual de Londrina, Caixa Postal 6001, 86051-970 Londrina, Paraná, Brasil.

2) Departamento de Zoologia, Universidade Estadual de Campinas, Caixa Postal 6109, 13081-970 Campinas, São Paulo, Brasil. 
The relation between each vocal sound identified and the general behaviour of the jays was documented by simultaneous announcements in all recordings and situations. The quantitative analysis was made by counting each category utterance by the captive individuals during periods of fifteen minutes. Eight periods were made in early morning, beginning with the first activity of the individuals, four around midday and three before sunset. Fourteen such samplings were obtained (Fig. 3).

A Uher $4400(19 \mathrm{~cm} / \mathrm{s})$ tape recorder, a parabolic reflector and microphone were used in the recordings. They were analysed on a "Voice Identification 700" sonograph at the Universidade Estadual de Campinas with the wide band filter $(300 \mathrm{~Hz})$ and linear scale $0-8 \mathrm{kHz}$. These recordings are stored in the Centro Paranaense de Bioacústica (originals), Universidade Estadual de Londrina, and the Arquivo Sonoro Neotropical (copies), Universidade Estadual de Campinas (Brazil); a selection of those is deposited in, and available from, the Bioacoustic Archive of the Florida State Museum (USA), catalogued as FM master 1197, and the British Library of Wildlife Sounds (UK).

\section{RESULTS}

\section{QUALITATIVE ANALYSES}

The repertoire of the Azure Jay is represented by two call types: the basic and the intermediate one.

\section{BASIC CALLS}

Fourteen basic calls were identified; they are shown as sonograms (Fig. 1) and are related to their probable function (Tab. I).

Contact call (Fig. 1a). This is a location call. Its acoustic structure, made of pseudopulses, has the characteristic which make it easily located.

Flight call (Fig. 1b). The flight call, like the contact call, is a location call, but it is usually uttered when the individual is flying, such as in flock displacement. Its structure is very similar to the contact call.

Social-call (Fig. 1c). This vocal sound is composed of a melodic note in arc form. It usually has a harmonic structure of $\mathrm{H} 2, \mathrm{H} 3$ and $\mathrm{H} 4$ in a decreasing order of amplitude. The social call stimulates approach if uttered by a member of the flock or by playback. This acoustic signal represents the song (or "advertising song") in the Azure Jay, as it conveys the biological function of speciesspecific recognition and thus follows the definition by VIELLIARD (1986); its playback provokes the strongest reaction and it has the farthest acoustic propagation among vocal sounds.

Social alarm call (Fig. 1d). In mobbing predators, the social call can often change to the social-alarm call. It consists of a note similar to that of the social call but with lesser frequency modulation and uttered in a faster cadence.

Proximity call (Fig. 1e). The proximity call is particularly common during up-fluffing and peck-preening behaviour. It has melodic tone with harmonic structure. 


\section{Frequency}

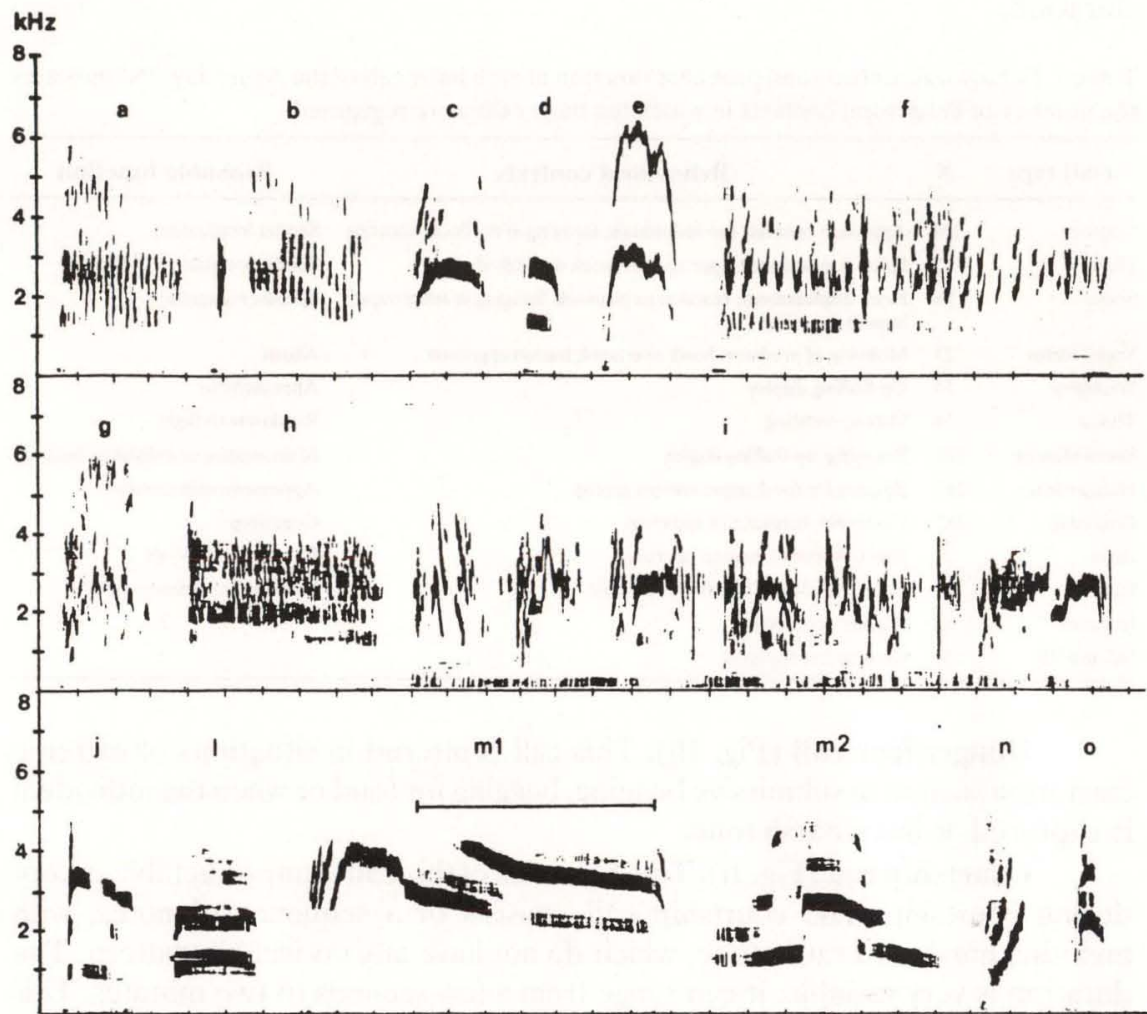

$\stackrel{\longleftrightarrow}{100 \mathrm{~ms}}$

Time

Figure 1. Basic calls of the Azure Jay. (a) Contact call (LDA 31/1/19); (b) flight call (LDA 38/2/3); (c) social call (LDA 32/14/60); (d) social-alarm call (23/1/11); (e) proximity call (LDA 39/14/1); (f) threat call (LDA 32/21/63); (g) social identity call (LDA 39/12/59); (h) hunger/fear call (LDA 24/4/89); (i) courtship call (LDA 31/16/66 - part of sequence); (j) alert call (LDA 31/2/31); (1) pair call (LDA 39/3/2); (m) imitative calls (m1-LDA 39/25/92 and m2- LDA 39/25/95); (n) "a" call (LDA 31/2/49); (o) "b" call (LDA 39/7/26).

Threat call (Fig. 1f). This acoustic signal was uttered during intraspecific agressive contact usually by the subordinate individual. The sound has amplitude and frequency modulation at the same time (rattle sound). The duration is related to the level of hostility; longer notes are common in highly hostile contexts.

Social identity call (Fig. 1g). The function of the social identity call seems to be the maintenance of individual distance. During roosting, this call was very common in subordinate individuals when the dominant one was nearby. Al- 
though it is similar to the contact call, this signal has higher frequency and shorter duration.

Table I. Behavioral contexts and probable function of each basic call of the Azure Jay. "N" indicates the number of behavioral contexts in which the basic calls were registered.

\begin{tabular}{lrll}
\hline \multicolumn{1}{c}{ Call type } & N & \multicolumn{1}{c}{ Behavioral contexts } & Probable function \\
\hline Contact & 181 & Approach between two individuals; foraging in the flock; roosting & $\begin{array}{l}\text { Sender localization } \\
\text { Flight }\end{array}$ \\
Social & 52 & Flock displacement; approach between two individuals & Sender localization in flight \\
& 96 & $\begin{array}{l}\text { Flock displacement; reaction to playback foraging in subgroups; } \\
\text { human approach }\end{array}$ & Specific recognition \\
Social-alarm & 23 & Mobbing of predator; bawk overhead; human approach & Alarm \\
Proximity & 54 & Up-fluffing display & Appeasement \\
Threat & 56 & Threat; roosting & Readiness to flight \\
Social identity & 128 & Roosting; up-fluffing display & Maintenance of individual distance \\
Hunger fear & 241 & Begging for food; appeasement gaping & Appeasement/necessity \\
Courtship & 202 & Courtship; context not apparent & Courtship \\
Alert & 22 & Hawk overhead; human approach & Danger notification \\
Pair & 17 & Before feeding of female by the male & Pair-bond communitation? \\
Imitative & 54 & Human approach & $?$ \\
"A" and "B" & 41 & Context not apparent & $?$ \\
\hline
\end{tabular}

Hunger/fear call (Fig. 1h). This call is uttered in situations of extreme excitation such as in submissive begging, begging for food or when the individual is captured. It has a harsh tone.

Courtship call (Fig. 1i). The utterance of this call is unpredictable except during courtship. The courtship call consists of a sequence of notes, with melodic, harsh and rattle tone, which do not have any noticeable pattern. The duration is very variable: it can range from a few seconds to two minutes. This call has restricted propagation in the environment so that the receiver must be within about six meters of the sender to hear it. HARDY (1961) names it sotto voce song.

Alert call (Fig. 1j). The alert call is related to predator presence, but while it is far off, without immediate danger. The alert call is composed of a melodic note with a harmonic structure and a slight arc form.

Pair call (Fig. 11). This was seldom noticed. It seems to be related to pair bond communication that takes place before the female is offered food by the male. This melodic note, with restricted propagation, has slight frequency modulation.

Imitative calls (Fig. 1m). Two calls resembled vocalizations of another bird species, the Roadside Hawk, Buteo magnirostris (Gmelin, 1788). Both calls have harmonic structure and long duration. Two sounds not harmonically related to each other are noticeable in one of the imitative calls (Fig. 1m 1, indicated by a bar). These two sounds are the result of the asynchronous control in each side of syrinx. GREENEWALT (1968) proves this phenomenon utilizing, as an example, a species as the same genus of the Azure Jay Cyanocorax yncas (Lesson, 1839). The sudden presence of a human near the cage stimulated 
the captive birds to utter these imitative calls.

"a" and "b" calls (Fig. 1n,o). Two calls could not be related to any particular behaviour, although they were uttered by birds during relaxation. Both of them have melodic structure and short duration.

\section{INTERMEDIATE CALLS}

The intermediate calls comprise recombinations of the basic calls uttered during an alteration in motivation level: they are structure linkages among the basic calls. They are very common in the Azure Jay's utterances; some examples are shown (Fig. 2).

In the laboratory, before the juvenile saw the caretaker, it emitted the social call (Fig. 2A). The hunger/fear call was emitted only when the bird saw the caretaker (Fig. 2B). During the food approach, a recombination of the social and hunger/fear calls was heard that could be short (Fig. 2C) or long (Fig. 2D).

Intermediate calls were noted during mobbing of a predator, a Roadside Hawk Buteo magnirostris. The social-alarm call (Fig. 2E-11) was the particular acoustic signal in mobbing a predator. But first, while the individuals of the flock were dispersed, the social call was uttered (Fig. 2E-7) for flock congregation. In that moment when the flock began the mobbing the social call changed to the social-alarm call. During this change three vocalizations were uttered (Fig. 2E$8,9,10)$, which are recombinations of the social and social-alarm calls.

Intermediate calls are very common in intraspecific agonistic contexts. The subordinate individual, with food in its bill, uttered the social identity call (Fig. 2F-7) when a dominant individual was nearby. The social identity call has the function of maintaining individual distance. If the dominant approached and tried to steal the food, the social identity call changed to the threat call (Fig. 2F-58). During this change, intermediate calls were uttered (Fig. 2F- 55,56,57).

\section{QUANTITATIVE ANALYSES}

The quantitative analyses was carried out by grouping the fourteen basic calls that were related to: sender localization (contact/flight calls), flock congregation (social/social-alarm calls), agonistic contexts (proximity/threat/social identity calls), mating (courtship call), necessity (hunger/fear call) and specific contexts (alert/pair/imitative/"a"/"b" calls). Only sender localization calls (especially in the morning) showed some regularity of utterance by day (small coefficient of variation); the utterances of the others, because they are related to a specific behavioral contexts, were more variable day by day.

The sender localization calls were the most uttered, principally in the morning during the highest activity of the individuals. The flock congregation calls were uttered most frequently in the early morning and before sunset. The agonistic context calls were commonly heard from individuals gathering in the middle of the day (during peck-preening activity) or for roosting. The sender localization, flock congregation and agonistic context calls were those most often uttered ( $84 \%$ of the utterances); the others made around $16 \%$ of the utterances (Fig. 3). 


\section{Frequency}

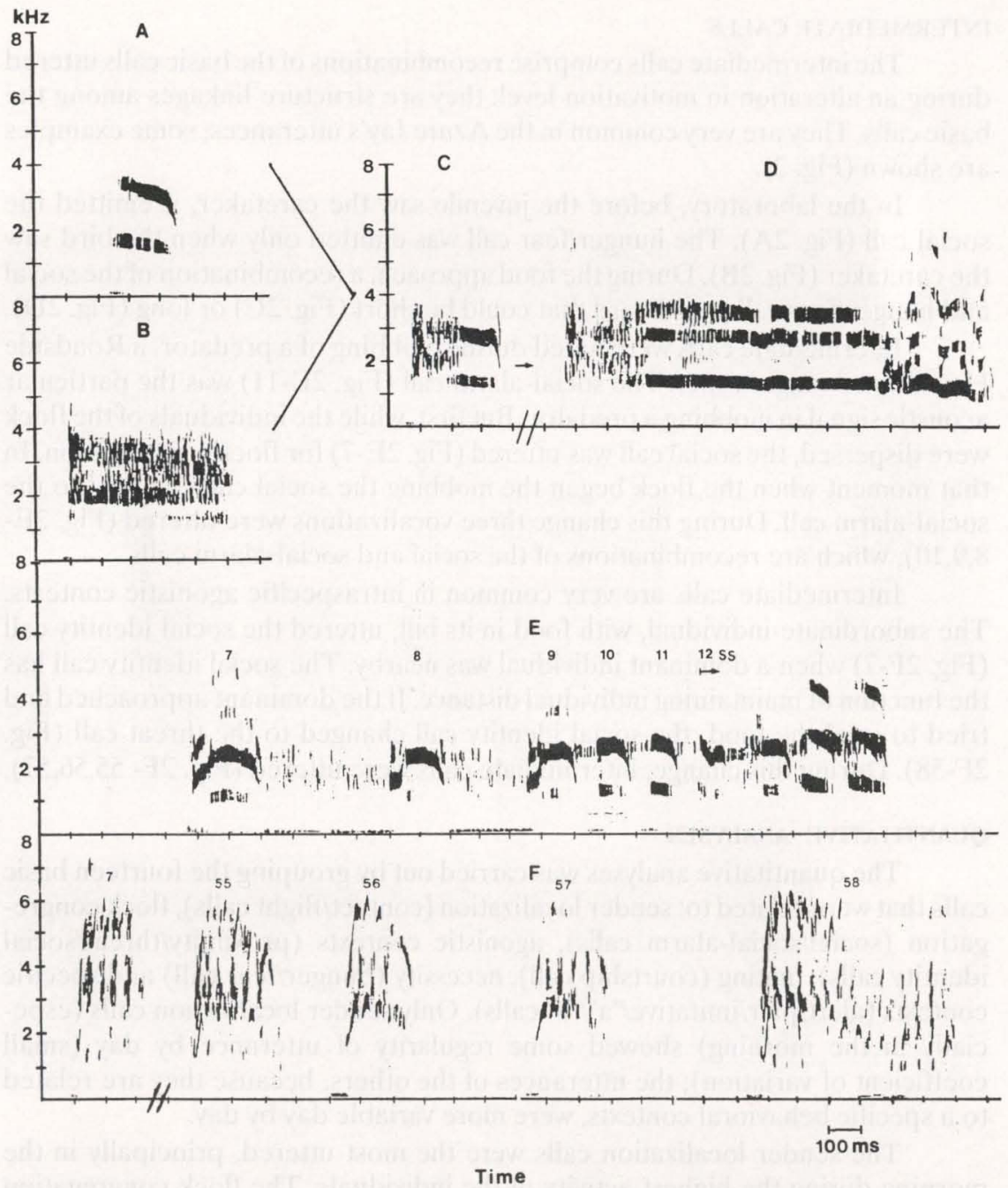

Figure 2. Intermediate calls of the Azure Jay. (A) social call of a fledgling (LDA 24/1/27); (B) hunger/fear call (LDA 24/34/89); (C,D) intermediate calls of a fledgling uttered during the food approach; the second part indicates the vocalization when the food is delivered (LDA 24/4/110; LDA 24/5/124); (E) intermediate calls (8-10) uttered between the social call (7) and the social alarm call (11-12ss); (F) intermediate calls (55-57) uttered between the social identity call (7) and the threat call (58) (LDA 39/7/7; LDA 39/12/55-58). Natural sequences, except where the time axis is broken. 


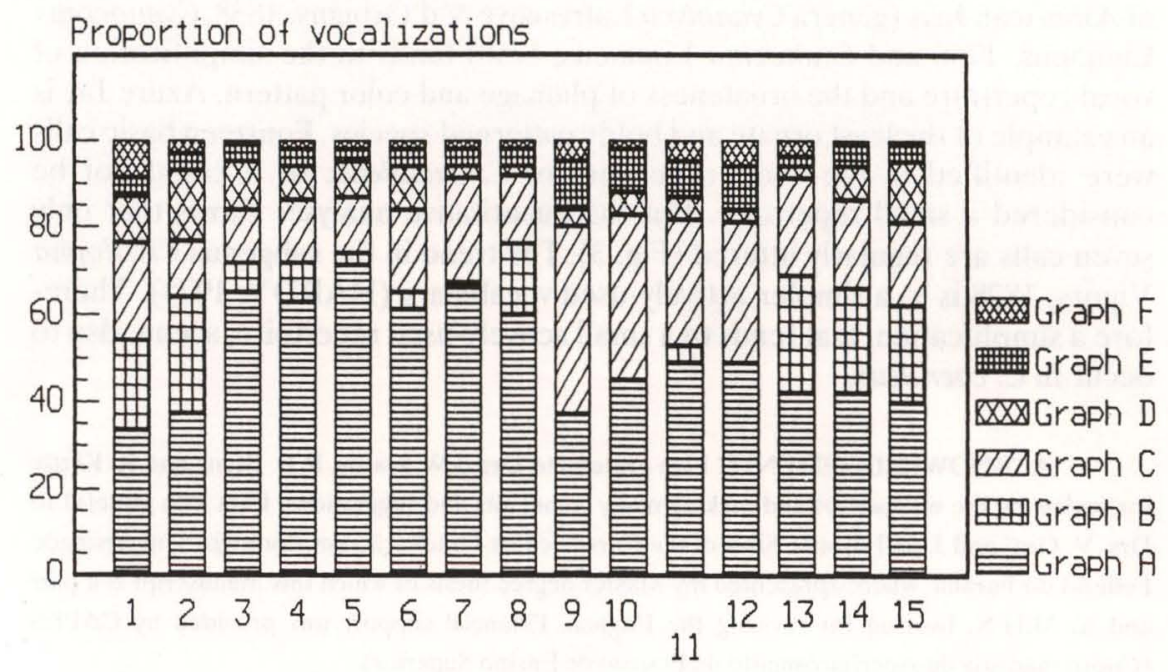

Periods of fifteen minutes

\begin{tabular}{|c|c|c|c|c|c|c|c|c|c|c|c|c|c|c|c|c|}
\hline \multirow{2}{*}{$\mathrm{CaIIs}$} & \multicolumn{16}{|c|}{ Periods } \\
\hline & 1 & 2 & 3 & 4 & 5 & 6 & 7 & 8 & 9 & 10 & 11 & 12 & 13 & 14 & 15 & Total \\
\hline $\mathrm{F}$ & 9 & 3 & 1 & 2 & 2 & 2 & 2 & 2 & 5 & 2 & 5 & 6 & 4 & 1 & 1 & 3 \\
\hline $\mathrm{E}$ & 4 & 4 & 4 & 4 & 3 & 4 & 4 & 4 & 11 & 10 & 8 & 10 & 2 & 5 & 4 & 5 \\
\hline D & 11 & 16 & 11 & 8 & 8 & 10 & 3 & 2 & 4 & 5 & 5 & 3 & 3 & 8 & 14 & 8 \\
\hline $\mathrm{C}$ & 22 & 13 & 12 & 14 & 13 & 19 & 24 & 16 & 43 & 38 & 29 & 32 & 22 & 20 & 19 & 21 \\
\hline B & 21 & 27 & 7 & 9 & 3 & 4 & 1 & 16 & - & - & 4 & - & 27 & 24 & 22 & 12 \\
\hline A & 33 & 37 & 65 & 63 & 71 & 61 & 66 & 60 & 37 & 45 & 49 & 49 & 42 & 42 & 40 & 51 \\
\hline
\end{tabular}

Figure 3. Proportion among the call categories express in percentage. Periods are in chronogical order, from the first to mid-morning (1-8), around midday (9-12) and before dusk (13-15). Fourteen such samples were obtained. The call categories are: (A) contact/flight calls; (B) social/social-alarm calls; (C) proximity/threat/social identity calls; (D) hunger/fear call; (E) courtship call; (F) alert/pair/imitative/"a"/"b" calls.

\section{DISCUSSION}

The vocal repertoire of $C$. caeruleus, because of the inclusion of the intermediate calls, comprises a continuous spectrum of recombinations from harsh to melodic and rattle sounds. Therefore the Azure Jay acoustic system achieves complexity through the combination of these sounds, rather than by a high diversity of discrete calls. A system like that is better suited for slight physiological and enviromental fluctuations, as already anticipated by MORTON (1977), because of the great number of possible recombinations. 
HARDY $(1961 ; 1969)$ hypothesized that the evolution in the "ornate" line of American Jays (genera Cyanolyca Lafresnaye \&'d'Orbigny, 1838, Cyanocorax Linnaeus, 1766 and Cyanocitta Linnaeus, 1758) tends to the simplification of vocal repertoire and the ornateness of plumage and color pattern. Azure Jay is an example of the least ornate and boldy patterned species. Fourteen basic calls were identified in the vocal repertoire of $C$. caeruleus; so it could not be considered a small repertoire. But the quantitative analyses shows that only seven calls are regularly uttered (Fig. 3). The trend in the subgenus Cissilopha Vigors, 1828 is to a simpler actively-used vocabulary (HARDY, 1974). Therefore a simplifcation, that tends to a small actively-used repertoire, seems also to occur in C. caeruleus.

ACKNOWLEDGEMENTS. I am grateful to Drs. J.W. Hardy, R.B. Payne and R. Kettle for reviewing the manuscript and making many comments and suggestions. I am also grateful to Drs. V. Graf and J. de Loyola e Silva of the Curso de Pós-Graduação em Zoologia, Universidade Federal do Paraná, where apresented my Master degree thesis of which this manuscript is a part and to M.H.N. Iwersen for revising the English. Financial support was provided by CAPES (Coordenadoria de Aperfeioamento de Pessoal de Ensino Superior).

\section{BIBLIOGRAPHIC REFERENCES}

GREENEWALT, C.H. 1968. Bird song: acoustics and physiology. Washington, D.C., Smithsonian Institution Press, 194p.

HARDY, J.W. 1961. Studies in behaviour and phylogeny of certain New World Jays (Garrulinae). University of Kansas Science Bulletin, 62 (2): 13-149.

- 1969. A taxonomic revision of the New World Jays. Condor 71: 360-375. . 1974. Behaviour and its evolution in Neotropical Jays (Cissilopha).

Bird-Banding 45 (3): 253-270.

. 1984. Voices of New World Jays, Crows \& theirallies: Family Corvidae. Gainesville, Florida, ARA Records-9.

MORTON, E.S. 1977. On the occurence and significance of motivation structural rules in some bird and mammal sounds. Am. Nat. 111: 855-869.

VIELLIARD, J.M.E. 1986. O uso da Bioacústica na Observação de Aves. In: Anais do II Encontro Nacional de Anilhadores de Aves, Universidade Federal do Rio de Janeiro, p.98-121.

Recebido em 11.X.1993; aceito em 28.II.1994. 